\title{
molecules
}

ISSN 1420-3049

http://www.mdpi.org

\section{Fabrication of Unimolecular Double-stranded DNA Microarrays on Solid Surfaces for Probing DNA-Protein/Drug Interactions}

\author{
Jinke Wang, Tongxiang Li, Yunfei Bai, Yi Zhu and Zuhong Lu* \\ Chien-Shiung Wu Laboratory, Southeast University, Nanjing 210096, P.R. China \\ * Author to whom correspondence should be addressed; E-mail: zhlu@ seu.edu.cn
}

\begin{abstract}
We present a novel method for fabricating unimolecular double-stranded DNA microarrays on solid surfaces, which were used to probe sequence-specific DNA/protein interactions. For manufacturing the unimolecular double-stranded DNA microarrays, two kinds of special single-stranded oligonucleotides, constant oligonucleotide and target oligonucleotide, were chemically synthesized. The constant oligonucleotides with internal aminated dT were used to capture and immobilize the target oligonucleotides onto the solid surface, and also to provide a primer for later enzymatic extension reactions, while target oligonucleotides took the role of harbouring DNA-binding sites of DNA-binding proteins. The variant target oligonucleotides were annealed and ligated with the constant oligonucleotides to form the new unimolecular oligonucleotides for microspotting. The prepared unimolecular oligonucleotides were microspotted on aldehyde-derivatized glass slides to make partial-dsDNA microarrays. Finally, the partial-dsDNA microarrays were converted into a unimolecular complete-dsDNA microarray by a DNA polymerase extension reaction. The efficiency and accuracy of the polymerase synthesis were demonstrated by the fluorescent-labeled dUTP incorporation in the enzymatic extension reaction and the restriction endonuclease digestion of the fabricated unimolecular complete-dsDNA microarray. The accessibility and specificity of the sequence-specific DNA-binding proteins binding to the immobilized unimolecular dsDNA probes were demonstrated by the binding of $\mathrm{Cy} 3$ labeled NF-?B (p50-p50) to the unimolecular dsDNA microarray. This unimolecular dsDNA microarray provides a general technique for high-throughput DNA-protein or DNA-drugs interactions.
\end{abstract}


Keywords: Fabrication, Unimolecular double-stranded DNA microarray, enzyme extension, DNA-protein interactions

\section{Introduction}

The interactions of DNA-binding proteins and DNA-binding drugs with double-stranded DNA (dsDNA) in the genome are involved in many important biological functions, including gene transcription regulation [1], DNA recombination [2], restriction [3], replication [4] and DNA-drug intercalation [5,6]. Therefore, lots of techniques including nitrocellulose-binding assays [7], gel mobility-shift analysis [8, 9], Southwestern blotting [10, 11], ELISA [12], reporter constructs in yeast [13], Chromatin immunoprecipitation (ChIP) [14], phage display [15], binding-site signatures [16], in- vitro selection [17], UV crosslinking [18], and methylization interfering assay [19] and X-ray crystallography $[20,21]$ were developed to effectively examine sequence-specific DNA-protein interactions, and also many techniques including UV absorption [22], melting temperature (thermodynamics) [23], NMR [24], X-ray crystallography [25, 26], free solution capillary electrophoresis (FSCE) [27], scanning force microscopy (SFM) [28-30], atomic force microscopy (AFM) [31], surface plasmon resonance (SPR) [32], polymerase chain reaction (PCR) [33, 34] and footprinting $[35,36]$ were used to effectively study DNA-drug interactions. However, these techniques using non-immobilized free dsDNAs in the liquid-phase to probe dsDNA interactions with other molecules such as proteins, ligands and drugs suffered from being laborious, time-consuming and incapable of high-throughput parallel analysis. Therefore, the solid surface-coupled dsDNA has become more and more important for high-throughput examination of sequence-specific DNA-protein interactions [37-39] and DNA-drug interactions [40-41], paving the way for new strategies for screening DNA-binding proteins [42], predicting DNA-binding sites [38, 39], assessing binding affinity [40-41] and screening sequence-specific DNA-binding drugs and finding drug-preferential sequences [40-41].

When the surface-coupled homogenous dsDNA were employed for examination of sequence-specific DNA-proteins or DNA-drug interactions, the number of classes of dsDNAs immobilized on a detectable solid entity determines how much information would be obtained in a single study. The surface-coupled homogenous dsDNAs were traditionally used in affinity chromatography to isolate the sequence-specific DNA-binding proteins [43-44] and the homogenous dsDNA probes immobilized on small paramagnetic particles were used to identify DNA-binding proteins by matrix-assisted laser desorption/ionization time-of-flight mass spectrometry (MALDI-TOF MS) [42]. These solid entities carrying homogenous dsDNAs suffered from the problem that they isolated or identified only one target molecule each time, therefore, they were not highly informative strategies for surface-coupled dsDNA applications. However, libraries of dsDNA oligonucleotides comprising a plurality of different members immobilized on a solid support much improved this limitation [45]. These solid-immobilized libraries of dsDNA oligonucleotides provided a useful 
technique for the screening of numerous biological samples by sequence-specific interactions [45]. Thereafter, the fabrication of fast, economical and high informative dsDNA-coupled solid entities became the pivotal problem for extensive surface-coupled dsDNA applications. Nevertheless, the earliest designed surface-immobilized libraries of different dsDNA oligonucleotides were fabricated by chemically synthesizing and immobilizing very long single-stranded DNA (ssDNA) oligonucleotides on solid surface and then forming unimolecular dsDNA oligonucleotides by intra-strand annealing self-complementery elements in immobilized long single-stranded oligonucleotides. This kind of surface-coupled dsDNA were high informative, but suffered from economic problems [45].

The appearance of high density bimolecular dsDNA microarrays greatly promoted the application of solid-immobilized duplex nucleic acids [37-41], and it is demonstrated that these high density bimolecular dsDNA microarrays were very effective for high throughput examination of DNA-protein interactions [38, 39] and DNA-drug interactions. However, the developments of these bimolecular dsDNA microarrays were slowed by several innate technical and economic drawbacks. The methods to manufacture bimolecular dsDNA microarrays could be divided into two types, one was by hybridization [40, 41, 46], and the other was enzymatic elongation [37]. The former spotted larger numbers of chemically synthesized ssDNA oligonucleotides onto solid surfaces to firstly fabricate a ssDNA microarray and subsequently converted this ssDNA microarray into a bimolecular dsDNA microarray by hybridizing the ssDNA microarray with a mixture of complementary ssDNA oligonucleotides. This method suffered from two main problems, one was high manufacturing costs resulting from amino-modification of immobilized ssDNA oligonucleotides and the second, complementary ssDNA oligonucleotide synthesis; the other more important problem was that the method could not fabricate dsDNA microarrays carrying very sequence-similar probes such as probes with single-nucleotide variations [40,41]. The latter on-chip photo-addressably synthesized high density ssDNA microarray with a constant sequence at far surface-attached 3' end of each oligonucleotides, and then annealed a general primer to constant sequence and performed enzymatic extension reactions on the array to convert ssDNA microarrays into bimolecular dsDNA microarrays. This method encountered more serious economic and technical issues. Technically, the method relied on currently expensive and proprietary technology for the surface photo addressable synthesis of oligonucleotides, but synthesis of single-stranded oligonucleotides on solid surfaces was inefficient, with per-nucleotide synthesis efficiencies thought to be only 92-96\% [47,48], for a 40-mer oligonucleotides, only $420 \%$ of the sequences on a chip could be of desired length and sequence [49]. In practice, oligonucleotide arrays constructed in this fashion are heavily contaminated with truncated molecules [47, 50]. Moreover, the presence of so many competing truncated molecules and single-stranded oligos not accessible to the primers might strongly interfere and mislead binding experiments [49]. Finally, considering the possible instability of bimolecular dsDNA oligos towards binding or washing reactions, the usefulness of this kind of bimolecular dsDNA microarrays might be diminished.

To overcome the drawbacks existing in previous dsDNA microarray techniques, we present a new method for economically fabricating unimolecular dsDNA microarrays which could be used many times. In this method, two kinds of special single-stranded oligonucleotides were firstly chemically 
synthesized for manufacturing unimolecular dsDNA microarrays, one was a target oligonucleotide harboring binding site of DNA-binding proteins and the other was a constant oligonucleotide for capturing, immobilizing DNA on glass slide and providing a primer for polymerization. The target oligonucleotides and the constant oligonucleotide were then annealed and ligated into the new unimolecular oligonucleotides, which were subsequently microspotted and immobilized on aldehyde-derivatized glass surfaces. Finally, we elongated the primer along the overhang template of unimolecular oligonucleotide with Klenow fragments to convert the partialdsDNA microarrays into unimolecular complete-dsDNA microarrays. We verified the feasibility of our method and demonstrated the sensitivity and specificity of detecting DNA-binding proteins with our dsDNA microarray.

\section{Materials and Methods}

\section{Synthesis of ssDNA Oligonucleotides}

Two kinds of special single-stranded oligonucleotides were chemically synthesized by Shengyou Inc. (Shanghai, China) for manufacturing dsDNA microarrays (listed in Table 1), one was a constant oligonucleotide (CO) consisting of a 7-base capture sequence at the 3' end and two 10-base reverse complementary sequences linked by an internal dT with a primary $\mathrm{NH}_{2}$ group (amino modifier C6) at the $5^{\prime}$ end. The other was a target oligonucleotide (TO) containing a 7-base proximal flanking sequence complementary to capture sequence of $\mathrm{CO}$, a randomized-base target sequence corresponding to DNA-binding sites of the sequence-specific DNA-binding proteins, and a distal flanking sequence from the $3^{\prime}$ to the $5^{\prime}$ end. The $3^{\prime}$ end of $\mathrm{CO}$ was hydroxyl and $5^{\prime}$ end was phosphate. Both $3^{\prime}$ and $5^{\prime}$ ends of TO were hydroxyl.

\section{Preparation of partial-dsDNA oligonucleotides}

The variant TOs were respectively annealed and ligated with pre-self-annealed COs in 1:1 molar ratio in a ligation reaction containing $40 \mathrm{mM}$ Tris- $\mathrm{HCl}(\mathrm{pH} 7.8), 10 \mathrm{mM} \mathrm{MgCl}, 10 \mathrm{mM}$ DTT, $0.5 \mathrm{mM}$ ATP and $0.5 \mathrm{U} / \mu \mathrm{T}$ T4 DNA ligase (MBI fermentas). The completed ligation reactions were exchanged into sodium carbonate buffer $(0.1 \mathrm{M}, \mathrm{pH} 9.0)$ at a concentration of $50 \mu \mathrm{M}$, by using CentriSpin- 10 spin columns (Princeton Separations, Adelphia, NJ).

\section{Manufacture of partial-dsDNA Microarrays}

Cleaned microscopy glass slides were silanized in $2 \%$ aminopropyltriethoxysilane (Sigma) dissolved in $95 \%$ acetone for $5 \mathrm{~min}$. After washing twice with acetone and baking for $45 \mathrm{~min}$ at $75^{\circ} \mathrm{C}$, the aminosilane slides were activated in glutaraldehyde solution $5 \%$ glutaraldehyde in $0.01 \mathrm{M} \mathrm{PB}$ at pH7.0) for $30 \mathrm{~min}$. The glutaraldehyde-activated slides were washed 3 times with distilled water and blown to dryness with $\mathrm{N}_{2}$. A PixSys5500 pin-based spotting robot (Cartesian Technology Inc.) with a CMP3 pin was employed to print the prepared oligonucleotides dissolved in sodium carbonate buffer 
$(0.1 \mathrm{M}, \mathrm{pH} 9.0)$ on glutaraldehyde-activated slides. After printing, the microarrays were kept in a humidity chamber containing sodium carbonate buffer $(0.1 \mathrm{M}, \mathrm{pH} 9.0)$ and incubated overnight at room temperature, and then followed by a incubation at $37^{\circ} \mathrm{C}$ for $1 \mathrm{~h}$ The rest of the aldehyde groups on slides were inactivated by a 30-min incubation in $0.28 \%(\mathrm{w} / \mathrm{v}) \mathrm{NaBH}_{4} / 76 \%$ (v/v) $\mathrm{PBS} / 24 \%$ (v/v) alcohol. After through washing in sterile double-distilled water $\left(\mathrm{ddH}_{2} \mathrm{O}\right)$, slides were spun dry in a clinical centrifuge and then stored in a close slide cassette at $4{ }^{\circ} \mathrm{C}$ until use.

\section{Fabrication of complete-dsDNA Microarrays}

The slides with prepared partialdsDNA microarrays were denatured in boiling water for 5 min and then incubated with hybridization buffer for $1 \mathrm{~h}$ at $50^{\circ} \mathrm{C}$. Subsequently, the slides were rinsed in turn with $2 \times \mathrm{SSC} / 0.1 \%$ SDS, $0.2 \times \mathrm{SSC} / 0.1 \%$ SDS and sterile $\mathrm{ddH}_{2} \mathrm{O}$. Thereafter, the partial-dsDNA microarrays were incubated with DNA polymerase reagent containing $50 \mathrm{mM}$ Tris- $\mathrm{HCl}(\mathrm{pH} 7.2), 10$ $\mathrm{mM} \mathrm{MgSO}_{4}, 0.1 \mathrm{mM}$ DTT, $40 \mu \mathrm{M}$ of each dNTP, $20 \mu \mathrm{g} / \mathrm{ml}$ acetylated BSA and $2 \mathrm{U} / \mu 1$ DNA polymera se I large (Klenow) fragment ( $3^{\prime}$ to $5^{\prime}$ exo ${ }^{-}$; Promega, Madison, WI). Detection of the enzymatic extension was accomplished by replacing the dTTP with Cy3-labeled dUTP (Pharmacia, Piscataway, NJ) in a DNA polymerase reaction. After extension reaction, the microarrays were respectively washed with $2 \times \mathrm{SSC} / 0.1 \% \mathrm{SDS}, 0.2 \times \mathrm{SSC} / 0.1 \% \mathrm{SDS}$ and sterile $\mathrm{ddH}_{2} \mathrm{O}$ for $10 \mathrm{~min}$ at room temperature. At last, the microarrays were dried in a clinical centrifuge and kept in closed cassette at $4{ }^{\circ} \mathrm{C}$ until use.

\section{Digestion of dsDNA Microarray with Restriction Endonuclease}

Hae IIIigestion of the dsDNA Microarray was performed at $37^{\circ} \mathrm{C}$ for $2 \mathrm{~h}$ by reaction with $10 \mathrm{mM}$ Tris- $\mathrm{HCl}(\mathrm{pH}$ 8.5), $10 \mathrm{mM} \mathrm{MgCb}, 100 \mathrm{mM} \mathrm{KCl,} \mathrm{0.02 \%} \mathrm{Triton} \mathrm{X-100,} 0.1 \mathrm{mg} / \mathrm{mL}$ BSA and $0.5 \mathrm{U} / \mu \mathrm{L}$ Hae III (MBI fermentas). After digestion, the slides were rinsed in turn with $2 \times \mathrm{SSC} / 0.1 \% \mathrm{SDS}$, $0.2 \times \mathrm{SSC} / 0.1 \% \mathrm{SDS}$ and sterile $\mathrm{ddH}_{2} \mathrm{O}$.

\section{Labeling of DNA-binding Proteins}

DNA-binding protein NF-?B (human recombinant p50 expressed in bacteria from a full-length cDNA encoding 453 amino acids) was purchased from Promega. The proteins provided in glycerol solutions were exchanged with BioRad Biospin P6 column into sodium carbonate-sodium bicarbonate buffer (pH9.3) at the concentration of $1 \mathrm{mg} / \mathrm{mL}$ and labeled with FluoroLink ${ }^{\mathrm{TM}} \mathrm{Cy} 3$ monofunctional dye (Amersham Pharmacia Biotech, Piscataway, NJ) at room temperature for $30 \mathrm{~min}$. After labeling, the protein solutions were exchanged with BioRad Biospin P6 column into glycerol-free, phosphate-buffer saline (PBS) solution (141 mM NaCl, $\left.7.2 \mathrm{mM} \mathrm{Na} 2 \mathrm{HPO}_{4}, 2.8 \mathrm{mM} \mathrm{NaH} \mathrm{PO}_{4}, \mathrm{pH} 7.4\right)$. The labeled proteins PBS solutions were aliquoted and kept at $4^{\circ} \mathrm{C}$ until use. 
Binding of DNA-binding Proteins to dsDNA Microarray

The dsDNA microarrays were blocked with 10\% BSA/ 0.01 M PBS for $1 \mathrm{~h}$ at room temperature, then washed with $0.01 \mathrm{M}$ PBS and spun dry. The blocked dsDNA microarrays were incubated with DNA-binding buffer (10 mM HEPES pH7.9, $50 \mathrm{mM} \mathrm{KCl,} 2.5 \mathrm{mM}$ DTT, $0.1 \mathrm{mM}$ EDTA, 0.05\% NP-40, 10\% Glycerol, 5\% BSA) containing Cy3 labeled NF-?B at room temperature for $1 \mathrm{~h}$. After incubation, the dsDNA microarrays were washed in turn with $0.01 \mathrm{M}$ PBS/0.05\% Tween 20 for $15 \mathrm{~min}$, and $0.01 \mathrm{M}$ PBS/0.01\% Triton 100 for $15 \mathrm{~min}$. Subsequently, the dsDNA microarrays were briefly washed with sterile $\mathrm{ddH}_{2} \mathrm{O}$ and spun dry in a clinical centrifuge. At last, the dsDNA microarrays were scanned with ScanArray® Lite of Packard Biochip Technologies in the Cy3 channel at 90\% laser power, 80\% PMT gain, $5 \mu \mathrm{m}$ resolution.

\section{dsDNA Microarray Data Analysis}

The signal intensities of the spots on microarray scanned false color images were quantified with QuantArray® microarray analysis software (Packard Biochip Technologies). The signal intensity of the spots refereed to the absolute signal intensity calculated by substracting the background fluorescence intensity from the detected signal intensity of spots.

\section{Results and Discussion}

\section{Scheme for dsDNA Microarray Fabrication}

The scheme for dsDNA microarray fabrication is illustrated in Figure 1. The main procedures were as follows. First, the $\mathrm{CO}$ was denatured and reannealed in a tube to form a hairpin-overhang structure. Second, the annealed CO was distributed into tubes containing variant heat-denatured Tos and the mixtures were incubated at the proper temperature for CO/TO hybrid ization. After hybridization, the bimolecular hairpin oligonucleotides with a long overhang were formed, which, however, contained a nick in the hairpin structure. Third, the DNA ligase was added into CO/TO hybridization reaction for eliminating the nick and thus forming the unimolecular hairpin oligonucleotides with a long overhang. Fourth, the CO/TO unimolecular hairpin oligonucleotides were microspotted and immobilized on aldehyde-derivatized glass surface by the primary $\mathrm{NH}_{2}$ group on the internal dT of $\mathrm{CO}$. After the procedure, the partialdsDNA microarrays were fabricated. Finally, the 3' end hydroxyls of the immobilized unimolecular hairpin oligonucleotides were elongated by DNA polymerase on the template of $5^{\prime}$ end single-stranded overhangs. After the Klenow polymerization, the partiatdsDNA microarrays were converted into complete dsDNA microarrays which harbored the DNA-binding sites of sequence-specific DNA-binding proteins. 


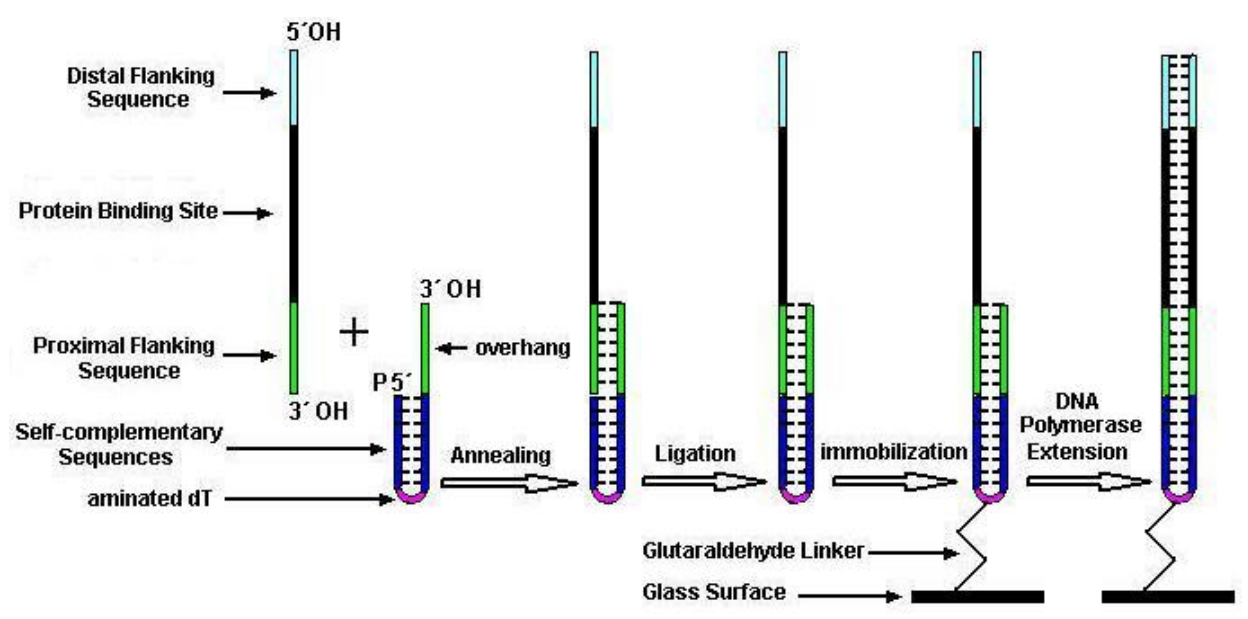

Figure 1. Scheme of the unimolecular dsDNA microarray fabrication

\section{Verification of CO/TO Annealing and Ligation}

To confirm the formation of the unimolecular hairpin oligonucleotides by TO/CO annealing and ligating reactions, we synthesized a 5'-end FAM-labeled AP2 TO and prepared three spotted DNA samples with it. The first was FAM-labeled AP2 TO annealed and ligated with CO, the second was FAM-labeled AP2 TO annealed but not ligated with CO, the third was FAM-labeled AP2 TO itself. The prepared three DNA samples were spotted on aldehyde-derivatized slides in triplet format. After immobilization, the slides were washed with $2 \times \mathrm{SSC} / 0.01 \%$ SDS and the fluorescence signals were collected with the standard FAM filter by laser scanning confocal microscope (Leica TCS SP) employing a $488 \mathrm{~nm}$ Ar ion laser.

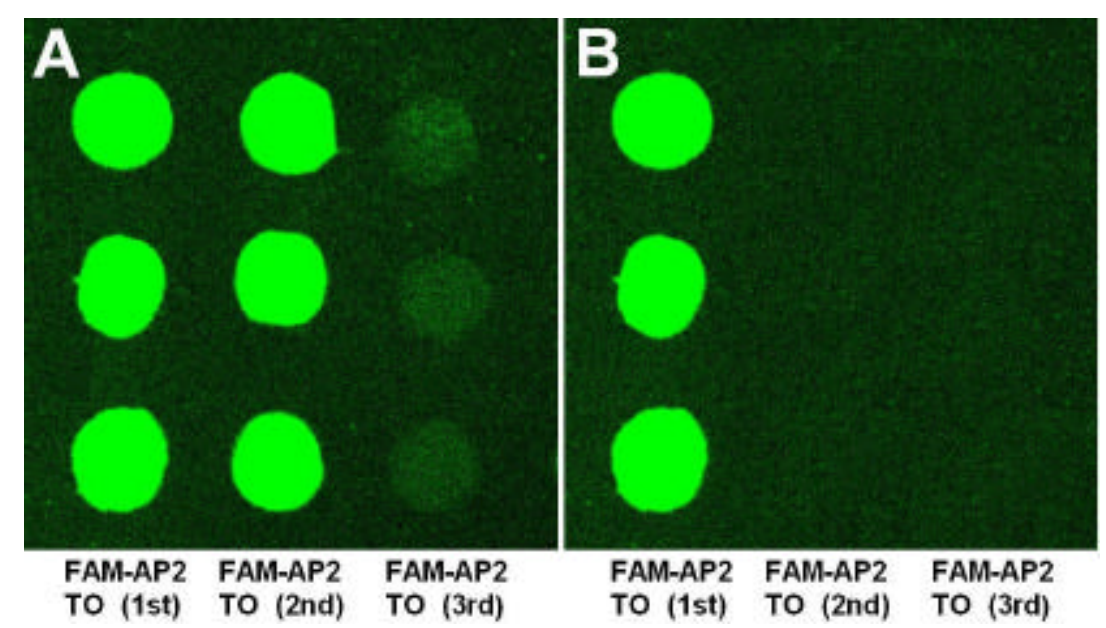

Figure 2. Fluorescence images of AP2 array before (A) and after (B) heat denaturation. FAM-AP2 TO (1st), FAM-AP2 TO (2nd) and FAM-AP2 TO (3rd) referred to FAM-labeled AP2 TO hybridized and ligated with CO, FAM-labeled AP2 TO hybridized but not ligated with CO, FAM-labeled AP2 TO itself respectively. 
The results are displayed in figure $2 \mathrm{~A}$, which reveal that the first and second DNA samples presented fluorescence signals, while the third DNA sample did not. Lacking a primary $\mathrm{NH}_{2}$ group, the third DNA sample of FAM-labeled AP2 TO itself could not immobilize on glass slides and emit fluorescence signals, which confirmed that the fluorescence signals displayed by the first and second DNA samples were CO-dependent. This implied that the FAM-labeled AP2 TOs in the first and second DNA samples annealed to COs. To further confirm the TO ligation with $\mathrm{CO}$, the above signal-collected slides were denatured in $100^{\circ} \mathrm{C}$ sterile $\mathrm{ddH}_{2} \mathrm{O}$ for $10 \mathrm{~min}$ and then washed with $0.2 \times \mathrm{SSC} / 0.01 \%$ SDS. After washing, the slides were rescanned with the previous laser channel. As expected, the fluorescence signals presented by the second DNA sample in the previous scanning disappeared, while that from the first DNA sample still existed (figure 2B). This verified that the FAM-labeled AP2 TO in the first DNA sample was successfully ligated with CO into a unimolecular oligonucleotide. Therefore, the FAM linked at $5^{\prime}$ end of the unimolecular oligonucleotide could not be destroyed by denaturing treatment. However, the FAM-labeled AP2 TO in the second DNA sample broke away from immobilized CO in denature because it only annealed with $\mathrm{CO}$ to form the bimolecular oligonucleotides which could be melted by heat. In all, the unimolecular oligonucleotides for microspotting can be reliably fabricated by DNA ligase.

\section{Validation of the Enzymatic Extension}

To verify the Klenow polymerization, the Klenow extension reactions with Cy3-labeled dUTP instead of dTTP were done with the unimolecular oligonucleotides microarray fabricated by AP1, AP2, SP1, TFIID and NF-?B TOs listed in Table 1.

Table 1. Oligonucleotides synthesized to fabricate DNA microarray

\begin{tabular}{|l|l|l|l|l|}
\hline \multirow{4}{*}{ \#\# } & \multirow{4}{*}{$\begin{array}{l}\text { Target } \\
\text { oligonucleotide }\end{array}$} & $\begin{array}{l}\text { Distal flanking } \\
\text { sequence }\end{array}$ & $\begin{array}{l}\text { Target } \\
\text { sequence }\end{array}$ & $\begin{array}{l}\text { Proximal flanking } \\
\text { sequence }\end{array}$ \\
\cline { 2 - 5 } & AP1 & CGCTTGA & TGAGTCA & CGTACGC \\
\cline { 2 - 5 } & SP1 & AATGTCC & $\begin{array}{l}\text { GCCCGCG } \\
\text { GC }\end{array}$ & CGTACGC \\
\cline { 2 - 5 } & TFIID & ACGATCG & GGGCGG & CGTACGC \\
\cline { 2 - 5 } & NS (NF-?B) & AGTTGAG & $\begin{array}{l}\text { GGGACTT } \\
\text { TCC }\end{array}$ & CGTACGC \\
\hline \multirow{2}{*}{$\begin{array}{l}\text { Constant } \\
\text { oligonucleotide }\end{array}$} & CO & \multicolumn{2}{|c|}{$\begin{array}{l}\text { P-GGAATCCCCC } \\
\text { GCGTACG-OH } \\
\text { (Aminated dT for immobilization is in bold) }\end{array}$} \\
\hline
\end{tabular}


The results are displayed in figure 3A. It demonstrated that the fluorescence signals were seen over the entire arrays incubated with Klenow reaction containing Cy3-dUTP, while no signal appeared over the control arrays incubated with Klenow reaction without Cy3-dUTP (not shown). The Klenow-dependent presentation of fluorescence signals confirmed the occurrence of Klenow polymerization on immobilized short unimolecular hairpin oligonucleotides. We subsequently examined the accuracy of Klenow polymerization by sequence-specific restriction endonuclease digestion. The above signal-presented microarrays were incubated with Hae? digestion reaction. The $\mathrm{Hae}$ ? -digested microarrays were rescanned and fluorescence signals were displayed in figure 3B, which demonstrated the fluorescence intensities of AP2 spots greatly decreased. It agreed with the fact that only AP2 unimolecular dsDNA oligonucleotide harbored Hae III digestion site (-GGCC-) and only two 5 end-anchored adenines in AP2 target oligonucleotide allowed Cy3-dUTP incorporation in Klenow polymerization. Therefore, we concluded that the Klenow extension could reach the distal terminals of immobilized oligonucleotides, and the high-fidelity enzymatically synthesized unimolecular dsDNA oligonucleotides on slides were accessible to sequence-specific restriction endonuclease.

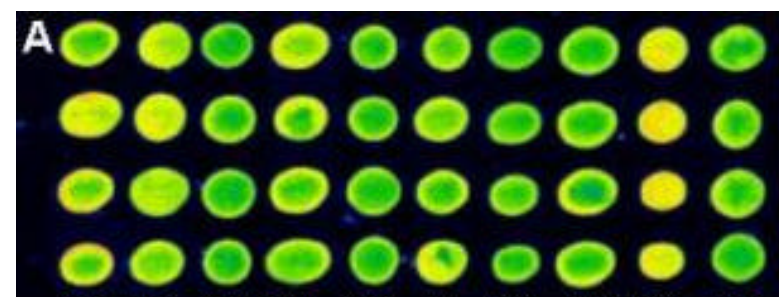

NS NS AP1 NS AP2 NS SP1 NS TFIID NS

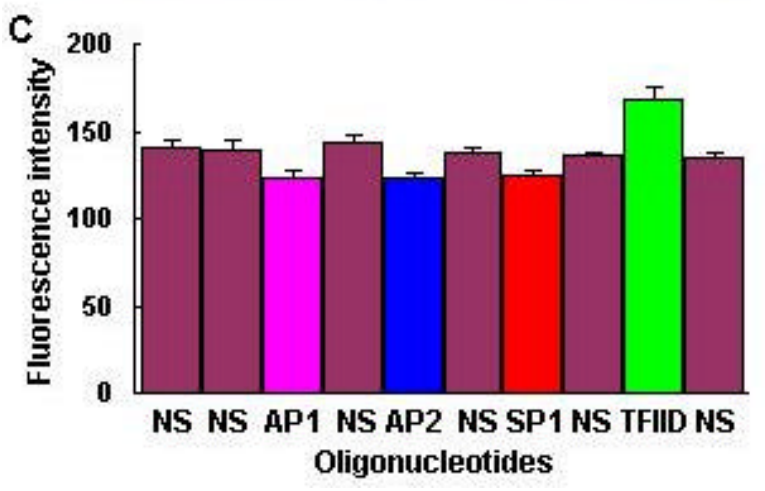

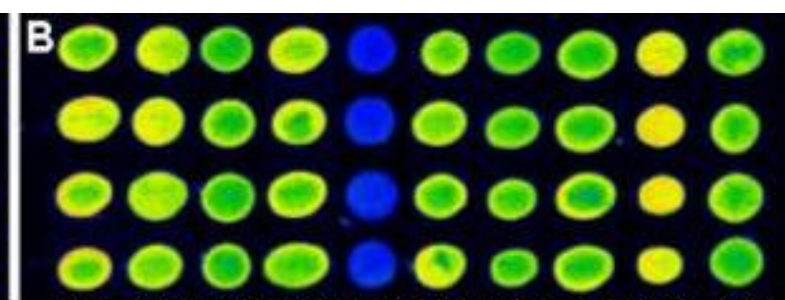

NS NS AP1 NS AP2 NS SP1 NS TFIID NS

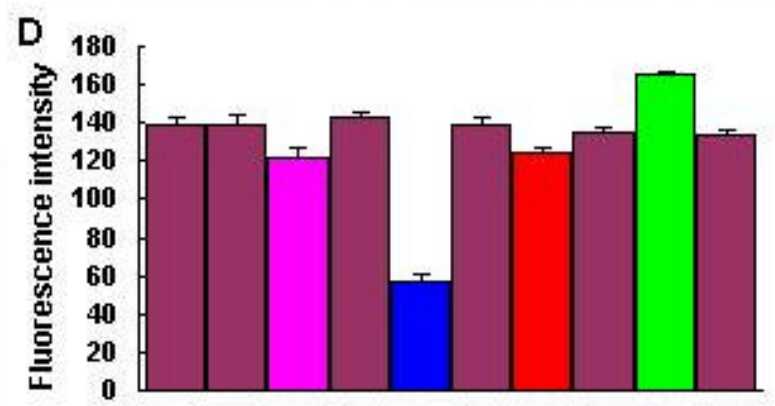

NS NS AP1 NS AP2 NS SP1 NS TFIID NS Oligonucleotides

Figure 3. Fluorescence images and intensity plots of the unimolecular dsDNA microarray fabricated by Klenow extension containing Cy3-labeled dUTP before (A and C) and after (B and D) HaeIII digestion.

Specificity of NF-?B p50 homodimer binding to DNA targets on dsDNA Microarray

As we aimed at fabricating unimolecular dsDNA microarray with general application value of study sequence-specific interactions between of DNA-binding proteins and dsDNA targets, we examined the 
sequence-specific accesiblity of transcription factor NF-?B to its target oligonucleotides immobilized on slides. We fabricated the unimolecular dsDNA microarrays with AP1, AP2, SP1, TFIID and NF-?B target oligonucleotides by Klenow reaction with unlabeled dNTPs. The fabricated microarrays were hybridized with Cy3-labeled NF-?B p50 homodimer and the scanned fluorescence signals were represented by Figure 4, which demonstrated that the NF- ?B p50 homodimer specifically bound to its target oligonucleotides on slides.

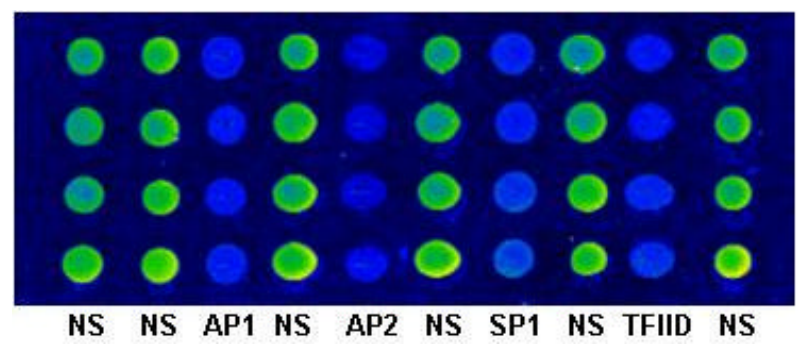

Figure 4. Fluorescence image of the unimolecular dsDNA microarray containing AP1, AP2, SP1, TFIID and NF-?B TOs hybridized with Cy3-labeled NF- $k$ B p50 homodimer.

To further verify the sequence-specificity, we hybridized 6 similar unimolecular dsDNA microarrays anchoring $6 \times 7 \mathrm{NF}-k \mathrm{~B}$ TOs (NS in Table 1) with 6 variant binding reactions containing the same concentrations of $\mathrm{Cy} 3$ - labeled NF- $k$ B p50 homodimer but 6 different concentrations of cold free NF- $k \mathrm{~B}$ dsDNA consensus oligonucleotides (Promega) sequencing identical to NS oligonucleotide.

A

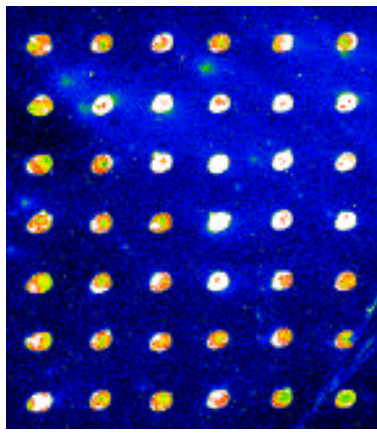

D

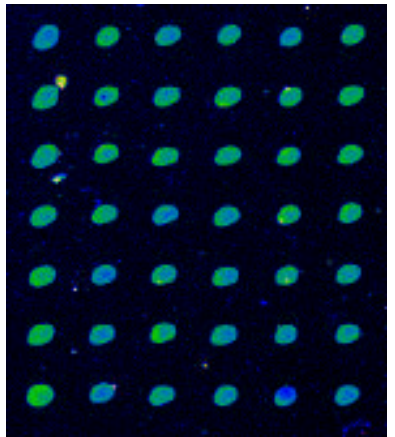

B

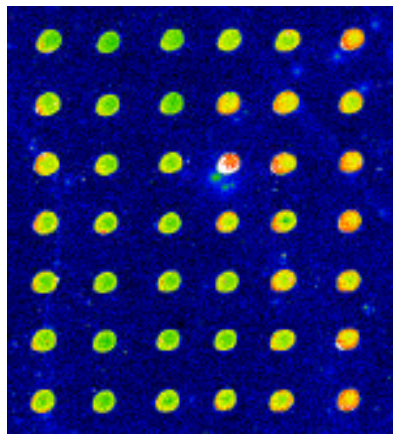

$\mathbf{E}$

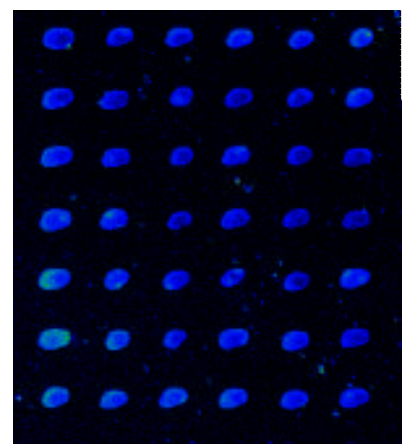

C
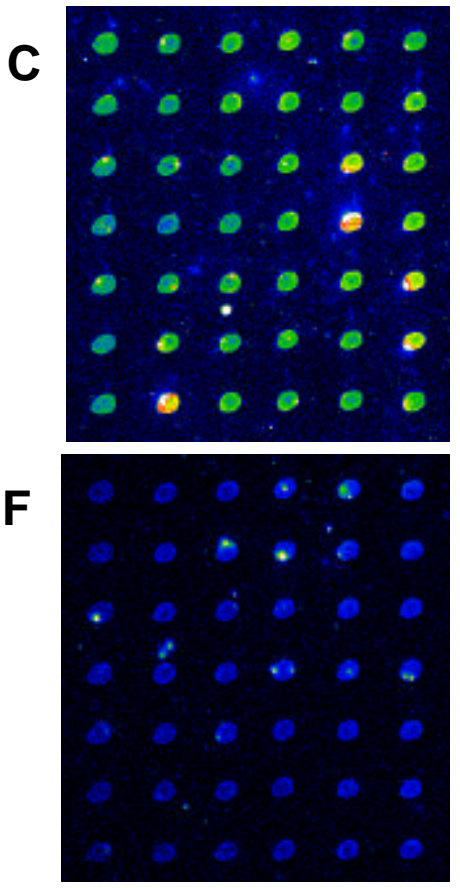


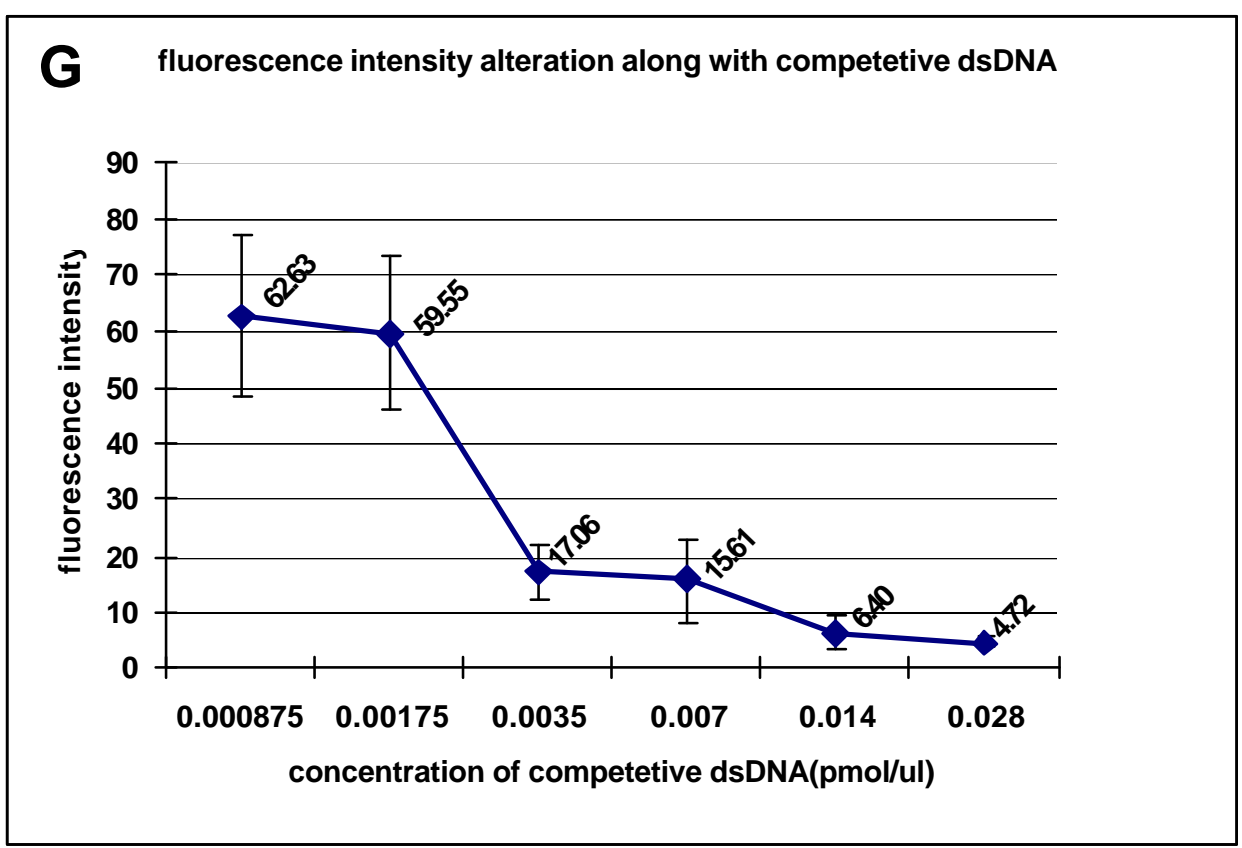

Figure 5. Fluorescence images and intensity plot of 6 dsDNA microarrays containing $6 \times 7$ NF- $k$ B TOs which were hybridized with 6 variant binding reactions containing same concentrations of $\mathrm{Cy} 3$-labeled $\mathrm{NF}-k \mathrm{~B}$ protein but 6 different concentrations of cold free NF- $k \mathrm{~B}$ dsDNA consensus oligonucleotides Promega) which nucleotide sequence was completely same as oligonucleotide NS in Table 1.

The results are displayed in Figure 5, which demonstrated that the fluorescence intensities decreased with the increase of cold free NF- $k \mathrm{~B}$ dsDNA consensus oligonucleotides in binding reactions. It revealed that the binding of NF- $k \mathrm{~B}$ to immobilized dsDNA targets could be restrained by specific competition. In all, the short unimolecular dsDNA oligonucleotides immobilized on slides could be specifically bound by DNA-binding protein as transcription factor.

\section{Sensitivity of Detecting NF-kBp50 homodimer with dsDNA Microarray}

From the above specific competition experiment, we found that the increase of free cold competitive dsDNA oligonucleotides decreased the amount of free NF- $k$ B in binding reaction, which correspondingly resulted in fluorescence intensity decreases. It implied that the unimolecular dsDNA microarray could be used to quantify NF- $k \mathrm{~B}$ in binding reaction. If the detected NF- $k \mathrm{~B}$ samples came from the nucleic extracts of cells, the fluorescence intensity resulted from these NF- $k$ B samples binding to unimolecular dsDNA microarrays would demonstrate the level of active NF- $k \mathrm{~B}$ in nucleus, which might related with certain inducements. However, as the amount of transcription factors in cells was very low, the sensitivity of unimolecular dsDNA microarrays examining NF- $k$ B was important. To 
determine the sensitivity of detecting target DNA-binding proteins with unimolecular dsDNA microarray, we hybridized 6 similar dsDNA microarrays anchoring $6 \times 7$ NF- $k$ B TOs (NS in Table 1) with 6 variant binding reactions containing 6 different concentrations of Cy3-labeled NF- $k$ B p50 homodimer.

A

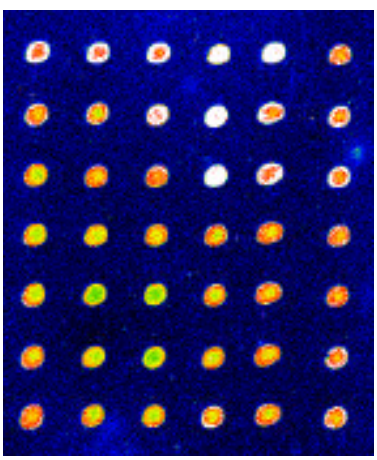

D

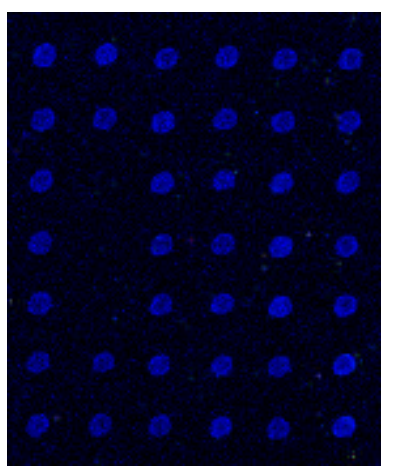

B

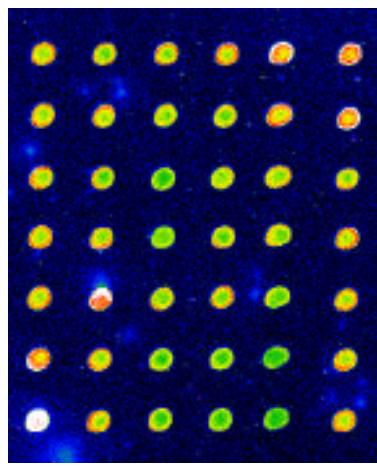

$\mathbf{E}$

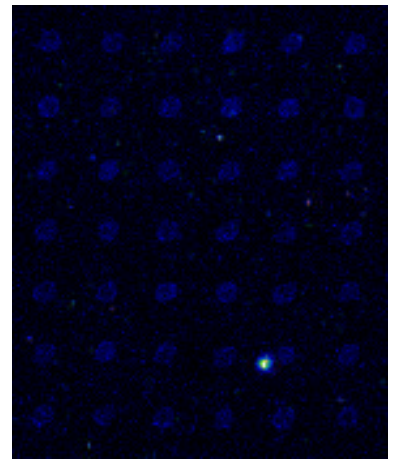

C

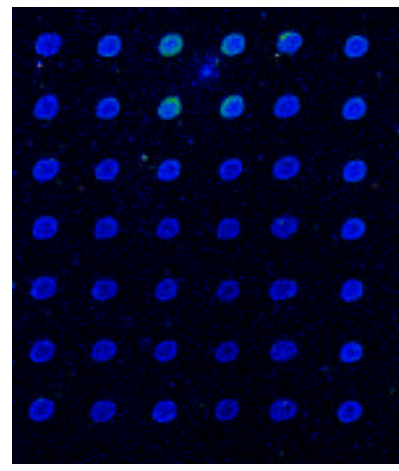

$\mathbf{F}$

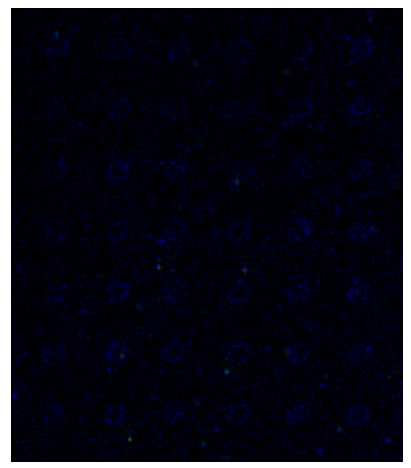

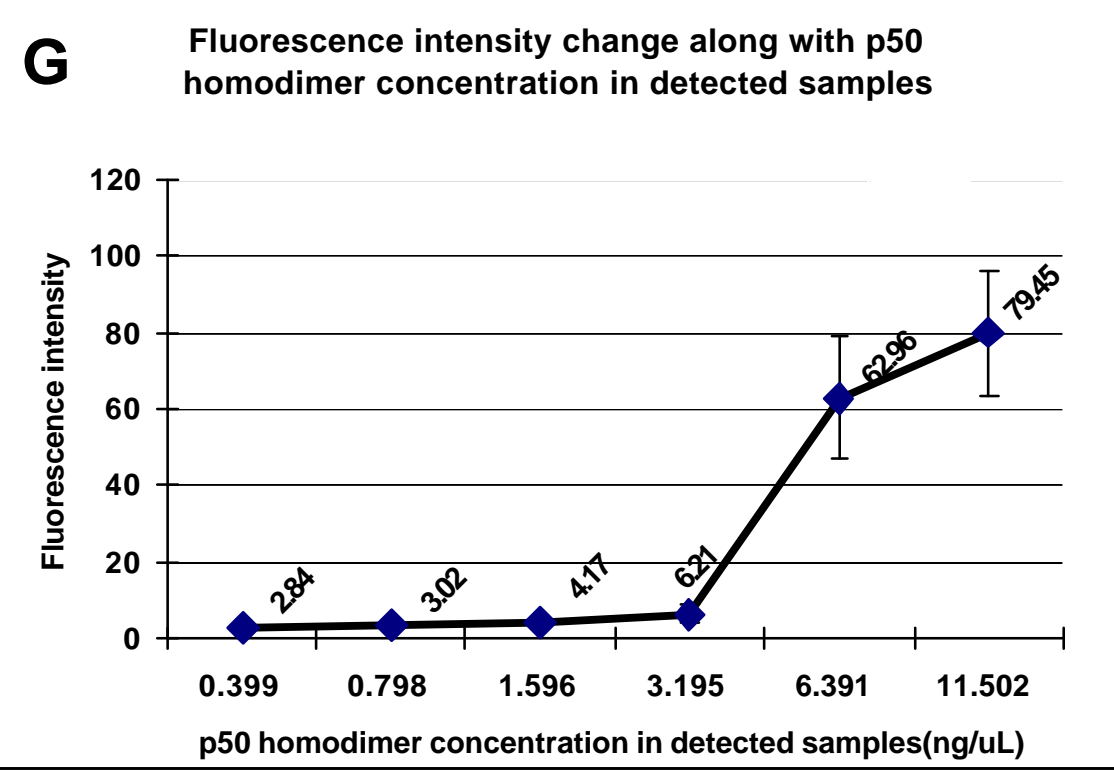

Figure 6. Fluorescence images and intensity plot of 6 dsDNA microarrays containing $6 \times 7$ NF- $k$ B TOs which were hybridized with 6 variant binding reactions containing different concentrations of Cy3-labeled NF- $k$ B protein. 
The results are displayed in Figure 6, which revealed that the signal intensities of microarrays coordinately decreased with the concentration of Cy3 labeled NF- $k \mathrm{~B}$ in samples. The dsDNA microarray allowed detection of Cy3 labeled NF-kB as few as $0.4 \mathrm{ng} / \mu \mathrm{l}(0.8 \mathrm{~mol} / \mathrm{ml})$ with very few

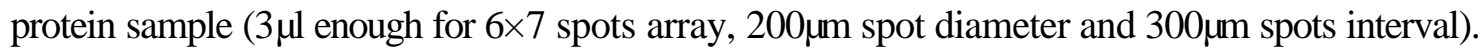

\section{Conclusions}

Church's lab saw the great potentials of dsDNA microarrays for studying sequence-specific DNA/protein interactions [37], and fabricated dsDNA microarray for exploring the DNA-binding specificities of zinc fingers with arrayed DNA targets [38, 39]. Their creative work verified the feasibility and high effectiveness of dsDNA microarrays in studying sequence-specific DNA/protein interaction. Nevertheless, their dsDNA microarray fabrication replied on the Affymetrix proprietary technology of photo-addressable oligonucleotide synthesis which is unaffordable for general laboratories until now. In this paper, we have presented a novel method for fabricating unimolecular dsDNA microarray and verified its reliability. This method has several significant advantages. Firstly, considering the expensive amino-labeling of oligonucleotides which cost was almost identical to target oligonucleotide synthesis (about 25 base pairs), the free constant oligonucleotide with amino modifier C6 dT was adopted to avoid repeatedly synthesizing long constant oligonucleotide with C6dT on each target oligonucleotides. This strategy can dramatically decrease the cost of unimolecular dsDNA microarray manufacture. Secondly, with free constant C6dT oligonucleotide, we only need to chemically synthesize target oligonucleotides for fabricating unimolecular dsDNA microarray. We testified that as short as 23bp (AP2) and 24bp (NF- $k$ B) oligonucleotides harboring protein-binding sites were long enough for proteins binding interaction. To synthesize so short single-stranded oligonucleotides also greatly lowers the cost of unimolecular dsDNA microarray manufacture. It avoids synthesizing long self-complementary single-stranded oligonucleotides for fabricating dsDNA oligonucleotides by annealing [45]. Thirdly, as the "second" complementary strands of oligonucleotides were enzymatically synthesized by DNA polymerase, it also greatly lowers the cost of unimolecular dsDNA microarray manufacture. Fourthly, as the exact complements of immobilized target oligonucleotides were synthesized by high-affinity Klenow DNA polymerase I, this method is competent for fabricating dsDNA microarray containing generic or homogenous dsDNA oligonucleotides with similar sequences as single nucleotide polymorphism (SNP). It overcomes the impossibility of fabricating generic or homogenous dsDNA, especially SNP dsDNA microarrays by hybridization [40, 41]. This is very important for dsDNA microarray applications to studying sequence-specific DNA/protein interactions. Fifthly, the enzymatically synthesized ultimate dsDNA oligonucleotides immobilized on glass were unimolecular nucleic acids, which can hold their function by reanneating after heat denature. Therefore, the unimolecular dsDNA microarray can be used for many times by removing bound proteins with stringent washing or heat denaturing. This far differs from bimolecular-dsDNA microarray [37-41]. Finally, this method of unimolecular dsDNA microarray fabrication accommodates with commercially available microarray spotting robots, it is reachable for extensive application. 
Our experiments revealed that the sequence-specific DNA-binding proteins as restriction endonuclease and transcription factor in detected samples could sensitively and specifically bind with dsDNA targets immobilized on microarray. This demonstrates that the method we presented in this paper provides a stable and affordable technique for fabricating the reusable unimolecular dsDNA microarray which could be used for high-throughput investigation of the interactions between biomolecules. The unimolecular dsDNA microarray could be potentially used to studies including (1) screening sequence-specific DNA-binding proteins, (2) predicting new DNA-binding sites of transcription factors in genome, (3) assessing importance of nucleotides in DNA-binding sites for DNA/protein interactions, (4) monitoring the expression of drug-induced DNA-binding proteins, and (5) screening sequence-specific DNA-binding drugs.

\section{Acknowledgements}

This work was supported by the Post-doctoral Scientific Foundation of China, the National Natural Science Foundation of China (60201005), and the National Science Fund for Distinguished Young Scholars (60121101).

\section{References}

1. Pabo, C.O; Sauer, R.T. Annu. Rev. Biochem. 1992, 61, 1053-1095.

2. Craig, N.L. Ann. Rev. Genet. 1988, 22, 77-105.

3. Pingoud, A.; Jeltsch, A. Eur. J. Biochem. 1997, 246, 1-22.

4. Margulies, C.; Kaguni, J.M. J. Biol. Chem. 1996, 271, 17035-17040.

5. Brazil, M. Nature Rev. Drug Discovery 2002, 1, 9.

6. Chaires, J. B. Curr. Opin. Struct. Biol. 1998, 8, 314-320.

7. Woodbury, C. P.; Hippel, P. H.V. Biochem. 1983, 22, 4730-4737.

8. Jansen, C., Gronenborn, A.M.; Clore, G.M. Biochem. J. 1987, 246, 227-232.

9. Ruscher, K.; Reuter, M.; Kupper, D.; Trendelenburg, G.; Dirnagl, U.; Meisel, A. J. Biotech. 2000, 78, 163-170.

10. Bowen, B.; Steinberg, J.; Laemmli, U.K.; Weintraub, H. Nucleic Acids Res. 1980, 8, 1-20.

11. Miskimins, W.K.; Roberts, M.P.; McClelland, A.; Ruddle, F.H. Proc. Natl. Acad. Sci. USA 1985, 82, 6741-6744.

12. Choo, Y.; Klug, A. Nucleic Acids Res. 1993, 21, 3341-3346.

13. Hanes, S.D.; Brent, R. Science 1991, 251, 426-430.

14. Olando, V. Trends Biochem. 2000, 25, 99-104.

15. Rebar, E. J. and Pabo, C. O. Science 1994, 263, 671-673.

16. Choo, Y.; Klug, A. Proc. Natl. Acad. Sci. USA 1993, 91, 11168-11172.

17. Oliphant, A.; Brendl, C.; Struhl, K. Mol. Cell Biol. 1989, 9, 2944-2949.

18. Escolano, A. L. G. R.; Medina, F.; Racaniello, V. R.; Angel, R. M. D. Virol. 1997, 227, 505-508.

19. Bilanges, B.; Varrault, A.; Basyuk, E.; Rodriguez, C.; Mazumdar, A.; Pantaloni, C.; Bockaert J.; Theillet, C.; Spengler, D.; Journot, L. Oncogene 1999, 18, 3979-3988. 
20. Müller, C. W.; Rey, F. A.; Sodeoka, M.; Verdine, G. L.; Harrison, S. C. Nature 1995, 373, 311-317.

21. Ghosh, G.; vanDuyne, G.; Ghosh, S.; Sigler, P.B. Nature 1995, 373, 303-310.

22. Dougherty, G.; Pigram, W. J. CRC Crit. Rev. Biochem. 1982, 12, 103-132.

23. Zimmer, C.; Luck, G. Advances in DNA Sequence Specific Agents. Hurley, L.H., ed, JAI Press Inc.: London 1992, vol. 1, pp. 51-88.

24. Searle, M.S. Prog. NMR Spectrosc. 1993, 25, 403-480.

25. Chaires, J.B. Advances in DNA Sequence Specific Agents. Hurley, L.H., ed, JAI Press Inc.: London 1992, Vol. 1, pp. 3-23.

26. Clark, G.R.; Boykin, D.W; Czarny, A.; Neidle, S. Nucleic Acids Res. 1997, 25, 1510-1515.

27. Hamdan,I. I.; Skellern G.G.; Waigh, R. D. Nucleic Acids Res. 1998, 26, 3053-3058.

28. Coury, J. E.; McFail-1som, L.; Williams, L.D.; Bottomley, L. A. Proc. Natl. Acad. Sci. USA 1996, 93, 12283-12286.

29. Coury, J. E.; Anderson, J. R.; McFail-Isom, L.; Williams, L. D.; Bottomley, L. A. J. Am. Chem. Soc. 1997, 119, 3792-3796.

30. Coury, J. E; Mcfail-Isom, L.; Williams, L. D.; Bottomley, L. A. Proc. Natl. Acad. Sci. USA 1996, 93, 12283-12286.

31. Berge, T.; Jenkins, N.S.; Honker, R. B.; Waring, J M. J.; Edwardson, M.; Henderson, R. M. Nucleic Acids Res. 2002, 30, 2980-2986.

32. Gambari, R.; Feriotto, G.; Rutigliano, C.; Bianchi, N.; Mischiati, C. J. Pharmacol. Exp. Ther. 2000, 294, 370-377.

33. Passadore, M.; Feriotto, G.; Bianchi, N.; Aguiari, G.; Mischiati, C.; Piva, R., Gambari, R. J. Biochem. Biophys. Methods 1994, 29, 307-19

34. Gambari, R. Biochemical Education 2000, 28, 100-103.

35. Broggini, M.; Ponti, M.; Ottolenghi, S.; D'Incalci, M.; Mongelli, N.; Mantovani, R. Nucleic Acids Res. 1989, 17, 1051-1059.

36. Keppler, M. D.; Neidle, S.; Fox, K. R. Nucleic Acids Res. 2001, 29,1935-1942.

37. Bulyk, M. L.; Gentalen, E.; Lockhart, D. J.; Church, G. M. Nat. Biotechnol. 1999, 17, 573-577.

38. Bulyk, M. L.; Huang, X.; Choo, Y.; Church, G. M. Proc. Natl. Acad. Sci. USA 2001, 98, 7158-7163.

39. Bulyk, M. L.; Johnson, P. L. F.; Church, G. M. Nucleic Acids Res. 2002, 30, 1255-1261.

40. Drobyshev, A.L.; Zasedatelev, A.S.; Yershov, G.M.; Mirzabekov, A. D. Nucleic Acids Res. 1999, 27, 4100-4105.

41. Krylov, A. S.; Zasedateleva, O. A.; Prokopenko, D. V.; Rouviere-Yaniv, J.; Mirzabekov, A. D. Nucleic Acids Res. 2001, 29, 2654-2660.

42. Nordhoff, E.; Krogsdam, A.M.; Jorgensen, H.F.; Kallipolitis, B.H.; Clark, B.F.C.; Roepstorff, P.; Kristiansen, K. Nat. Biotechnol. 1999, 17, 884-888.

43. Kadonaga, J.T.; Tjian, R. Proc. Natl. Acad. Sci. USA 1986, 83, 5889-5893.

44. Kadonaga, J.T. Methods Enzymol. 1991, 208, 10-23.

45. Lochart, D.J.; Vetter, D.; Diggelmann, M. US patent 5,556,752, 1996.

46. Braun, E.; Eichen, Y.; Sivan, U.; Ben-Yoseph, G. Nature 1998, 391, 775-778. 
47. McGall, G. H.; Barone, A. D.; Diggelmann, M.; Fodor, S. P. A.; Gentelen, E.; Ngo. N. J. Am. Chem. Soc. 1997, 119, 5081-5090.

48. Southern, E.M.; Mir, K.; Shchepinov, M. Nat. Genet. (Suppl.) 1999, 21, 5-9.

49. Carlson, R.; Brent, R. Nat. Biotech. 1999, 17, 536-537.

50. Kwiatkowski, M.; Fredriksson, S.; Saksson, A.; Nilsson, M.; Landegren, U. Nucleic Acids Res. 1999, 27, 4710-4714.

(C) 2003 by MDPI (http://www.mdpi.org). Reproduction is permitted for noncommercial purposes. 